\title{
Cytoplasmic Transfer of Chloramphenicol Resistance in Chinese Hamster Cells
}

\author{
Richard C. K. Yen and Morgan Harris \\ Department of Zoology and Cancer Research Laboratory, University of Cali- \\ fornia, Berkeley, California
}

\begin{abstract}
Chloramphenicol resistance, a dominant marker, is readily transferred between Chinese hamster cells by fusing enucleated cytoplasts from resistant cells to a sensitive recipient strain. Isolation of cytohybrids depends on complementary selection for recessive characteristics present in recipient cells, e.g. resistance to bromodeoxyuridine. Sources of background variation in this system have been examined to determine the efficiency of cytoplasmic marker transfer. The frequency of mutants resistant to both chloramphenicol and bromodeoxyuridine was minimal in the parent strains used. Dual resistance was found to arise, however, by segregation within hybrids formed between nucleated cells present as contaminants in cytoplast fusion mixtures. Background variation may also simulate cytoplasmic transfer of nuclear markers from donor cells (e.g. resistance to ouabain). Cytohybrids resistant to both ouabain and chloramphenicol were in fact isolated from cytoplast fusion mixtures by selection with ouabain and bromodeoxyuridine. Such variants appeared to originate by mutation to ouabain resistance in recipient cells followed by cytoplasmic transfer of the chloramphenicol resistance marker.
\end{abstract}

Cytoplasmic inheritance is the subject of rapidly expanding studies in lower eukaryotes (1-3) but remains largely unexplored at the mammalian level, in part because the necessary genetic markers remain to be defined. The initial steps in this development, however, have been taken by Eisenstadt and his collaborators (4-7), who have shown that chloramphenicol resistance in mouse and human cells can be transmitted by fusing enucleated cytoplasts to sensitive recipient strains. Mitochondria from these cytohybrids and from the original donor strain showed altered responses to chloramphenicol in vitro. A reasonable inference is that chloramphenicol resistance in mammalian cells is coded for by a mutant mitochondrial gene, as in yeast and protozoa.

Chinese hamster cells offer another model for such studies. These lines have been widely used for genetic analysis $(8,9)$, but have not hitherto been examined for antimitochondrial resistance markers. In the present experiments we show that chloramphenicol resistance $\left(\mathrm{CAM}^{\mathrm{R}}\right)$ in Chinese hamster cells can be conferred in high frequency by cytoplasmic transfer. Background variation is significant in this system, and must be carefully controlled. The analysis of these changes is detailed in the sections which follow, and provides a baseline for genetic studies. 


\section{MATERIALS AND METHODS}

Cell lines. Two lines of cells were used. The first of these, BI-50, originated as a bromodeoxyuridine-resistant $\left(\mathrm{BUDR}^{\mathrm{R}}\right.$ ) subline of Chinese hamster peritoneal cells (10). BI-50 cells lack thymidine kinase (TK) and are sensitive to chloramphenicol and ouabain $\left(\mathrm{CAM}^{\mathrm{s}}\right.$, OUA s). They were accordingly used as recipient cells in fusion experiments utilizing these drugs. Donor cells for enucleation and cytoplasmic transfer were derived from line 204. This strain is a derivative of V79 lung cells (11) and was obtained by a sequence of selective steps. Line 129 was first isolated (12) as an azaguanine-resistant $\left(\mathrm{AZG}^{\mathrm{R}}\right)$ mutant lacking hypoxanthineguanine phosphoribosyltransferase (HGPRT). By selection with chloramphenicol a $\mathrm{CAM}^{\mathrm{R}}$ subline was obtained and converted to a tetraploid population by treatment with colcemid (13). The purpose of this conversion was to obtain large cytoplasts for enucleation studies. Finally, doubly resistant clones were isolated from the tetraploid cells by selection in ouabain. Clone $204\left(\mathrm{CAM}^{\mathrm{R}}\right.$ OUA $\left.^{\mathrm{R}}\right)$ is one of these and was used as cytoplast donor in all the enucleation and fusion experiments.

Culture methods. Stock populations of all cells were maintained as monolayers in prescription bottles (Brockway Glass Co.) in nutrients containing 10\% fetal calf serum (Flow Laboratories) and $90 \%$ Dulbecco's modification of Eagle's medium (10FCSDB). Sodium penicilline $\mathrm{G}(60 \mu \mathrm{g} / \mathrm{ml})$, streptomycin $(50 \mu \mathrm{g} / \mathrm{ml})$, and L-glutamine $(100 \mu \mathrm{g} / \mathrm{ml})$ were added to the final nutrient. HAT medium (14) was prepared by supplementing 10FCSDB with $1 \times 10^{-4}$ $\mathrm{M}$ hypoxanthine, $4 \times 10^{-7} \mathrm{M}$ aminopterin, and $1.6 \times 10^{-5}$ thymidine. Ouabain (OUA) and chloramphenicol (CAM) were obtained from Calbiochem. For convenience, the concentration of these and other drugs is expressed in the text in $\mu \mathrm{g} / \mathrm{ml}$ by numbers preceding the drug symbol, e.g. 100 CAM, 30 BUDR. Plating experiments were carried out in $60 \mathrm{~mm}$ petri dises (Falcon Plastics and Lux Scientific Corp)., which were incubated at $37^{\circ} \mathrm{C}$ in a humidified $\mathrm{CO}_{2}$ incubator. Other details of culture procedures may be found in preceding papers $(15,16)$. All cell lines were monitored at intervals by culture methods for the presence of mycoplasma; none were found.

Eucleation. The procedure of Prescott (17) was used with modifications as follows. Cytochalasin B (CB, Aldrich Chemicals) was dissolved in dimethylsulfoxide for addition to the culture medium. Cells to be enucleated were grown initially for one day on $25 \mathrm{~mm}$ round plastic cover slips (Lux Scientific Corp.) in 10FCSDB. For enucleation, the cover slips were inserted into $50 \mathrm{ml}$ polypropylene tubes (cell side down) in $12.5 \mathrm{ml}$ 10FCSDB containing 4-7 $\mu \mathrm{g} / \mathrm{ml} \mathrm{CB}$. The tubes were then placed in a Sorvall RC-2 centrifuge, using an SS-34 rotor pre-warmed to $37^{\circ} \mathrm{C}$. Maximum enucleation of line 204 cells was obtained by centrifugation at $12,000 \mathrm{RPM}(17,300 \mathrm{~g})$ for 10 minutes, after which the cover slips were transferred to petri dishes containing 10FCSDB without CB. Recovery of normal morphology was complete after 30 minutes at $37^{\circ} \mathrm{C}$. Two or more cover slips from each run were fixed and stained to determine the effectiveness of this procedure. The fraction of cells enucleated was consistently $90 \%$ or more.

Cell fusions. Enucleated 204 cells (cytoplasts) were fused with nucleated recipient cells (BI50 ) in the following manner. The entire population from several cover slips (cytoplasts plus a minority of donor cells which escaped enucleation) was dispersed with $0.1 \%$ trypsinversene, pooled, and enumerated with a Coulter Counter, Model B. An appropriate sample, usually $0.75 \times 10^{6}$ cytoplasts, was mixed with $3.0 \times 10 \mathrm{BI}-50$ cells, pelleted by light centrifugation, and resuspended in Dulbecco's medium without serum, but buffered to $\mathrm{pH} 7.8$ with $15 \mathrm{mM}$ HEPES and $15 \mathrm{mM}$ Tricine (HT-DB). Sendai virus (inactivated by $\beta$-propiolactone) was added to a final concentration of $1000 \mathrm{HAU} / \mathrm{ml}$. After 15 minutes at $4^{\circ} \mathrm{C}$, the fusion 
mixture was again pelleted, resuspended in fresh HT-DB, and incubated at $37^{\circ} \mathrm{C}$ with gentle agitation for 30 minutes. The cells were then diluted and plated into petri dishes at densities ranging from $2.5 \times 10^{4}$ to $0.5 \times 10^{6}$ per culture. As shown in the next section, two types of hybrids arise in these assay cultures; (1) hybrids between cytoplasts and nucleated recipient cells, and (2) hybrids of the usual type between two nucleated parent cells. To avoid ambiguity, the former will be referred to as cytohybrids and latter will be designated euhybrids.

\section{RESULTS AND DISCUSSION}

Transmission of CAM resistance. Figs. 1 and 2 illustrate the drug resistance markers utilized in the present study. Dose-response curves are shown for 204 donor cells, BI-50 recipient cells, and for several related lines in graded CAM and OUA. No cross-resistance or interaction between the two inhibitors was seen. The data show that ploidy differences did not affect plating in OUA, and had only a minor effect on cells in CAM. Donor and recipient cells in this system can also be distinguished by chromosome markers characteristic of cells from V79 and BI-50 lineages respectively (12). Key differences, reaffirmed in the present study, are the consistent presence of small acrocentric chromosomes in 204 cells as compared to their near absence in the BI-50 line, and a greater number of small metacentric chromosomes in BI-50 cells. These distinctions are diagnostic for donor and recipient cells in mixtures, and for the separation of cytohybrids from euhybrids.

Table 1 summarizes the data obtained in a series of experiments designed to isolate $\mathrm{CAM}^{\mathrm{R}}$ cytohybrids from mixtures of clone 204 cytoplasts and BI-50 indicator cells. Selective media contained CAM + BUDR, to which the parental cells and euhybrids, but not the cytohybrids, were sensitive. The incidence of colonies appearing from mixtures of cytoplasts and BI-50 cells was greatly in excess of that found in mixtures of whole cells (reconstruction controls), or in cultures of parental cells alone. The absolute number of colonies observed depended on the level of CAM used for selection, and on the ratio of cytoplasts to indicator cells (compare experiments 2 and 3 ).

We isolated 71 clones from mixtures of cytoplasts and indicator cells in 100 $\mathrm{CAM}+30$ BUDR, and subcultured the derivative populations for further study. Detailed karyotypic studies were made on 6 of these. In all cases, the putative cytohybrids closely resembled BI-50 cells in chromosome number and pattern. Assuming that such cells contain a mixture of $\mathrm{CAM}^{\mathrm{R}}$ and $\mathrm{CAM}^{\mathrm{S}}$ mitochondria initially, a spectrum of sensitivity to CAM would be expected in clonal isolates. In accordance with this prediction, we found that all 71 of the clones tested grew progressively in 10FCSDB and most in 30 CAM, but only 52 of 71 did so in 100 CAM. The same clones were examined for the $\mathrm{OUA}^{\mathrm{R}}$ marker which had been present in the original donor cells. Significantly, none of the 71 clones grew in media supplemented with 1000 OUA. Thus, there was no indication that the OUA ${ }^{R}$ marker could be cotransferred by cytoplasts in a CAM selection system.

Analysis of background variation. The contribution of background changes must be assessed quantitatively in order to determine the actual frequency of cytohybrids in fusion mixtures. Table 1 shows that $\mathrm{CAM}^{\mathrm{R}}$ variants were present at a low frequency in BI-50 populations, and that the number scored was higher in assays with 30 CAM than with 100 CAM. Similarly, a small number of BUDR ${ }^{R}$ variants appeared in some control series with intact 204 donor cells. Variation in either case, however, accounted for less than $1 \%$ of the colonies observed in mixtures of cytoplasts and recipient cells. 


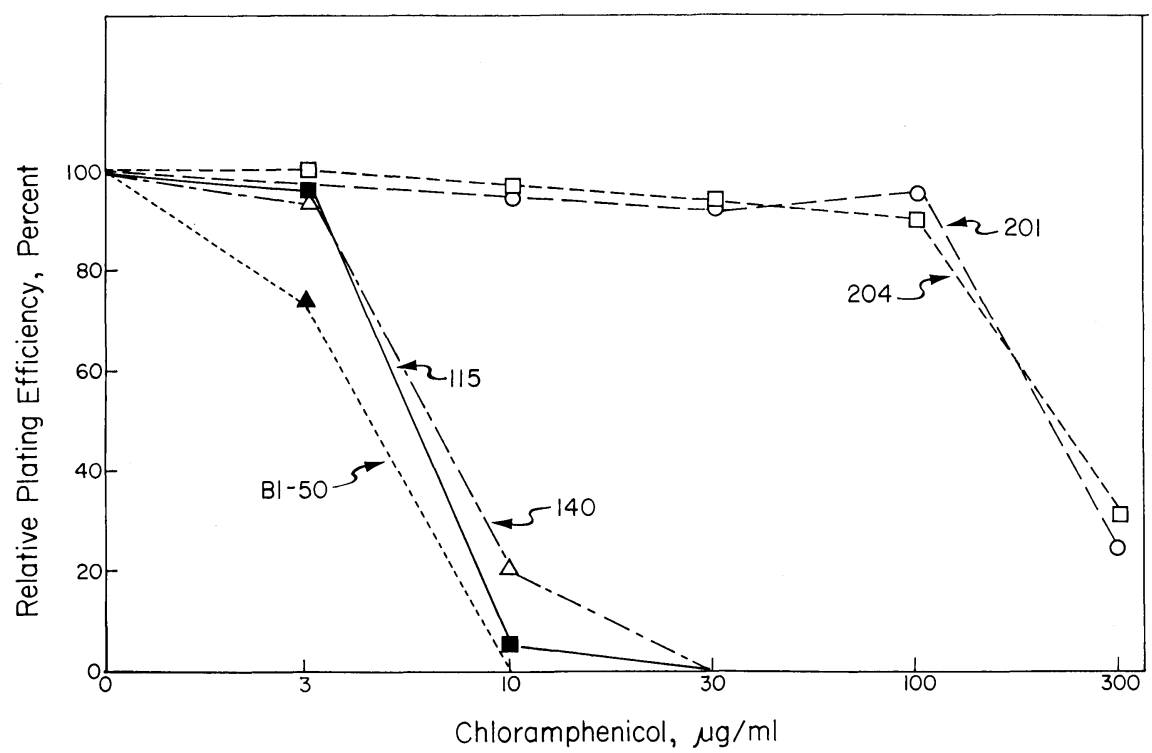

Fig. 1. Relative plating efficiency of 204 donor cells and BI-50 recipient cells in graded levels of CAM. Several related lines are also shown. Line 140 is a tetraploid derivative of BI-50. Lines 115 and 201 originated from V79 cells and are diploid, CAM ${ }^{\mathrm{S}} \mathrm{OUA}^{\mathrm{R}}$, and tetraploid, $\mathrm{CAM}^{\mathrm{R}}$ OUA $^{\mathrm{S}}$ respectively. Each point represents an average value for counts made on three or more petri dish cultures.

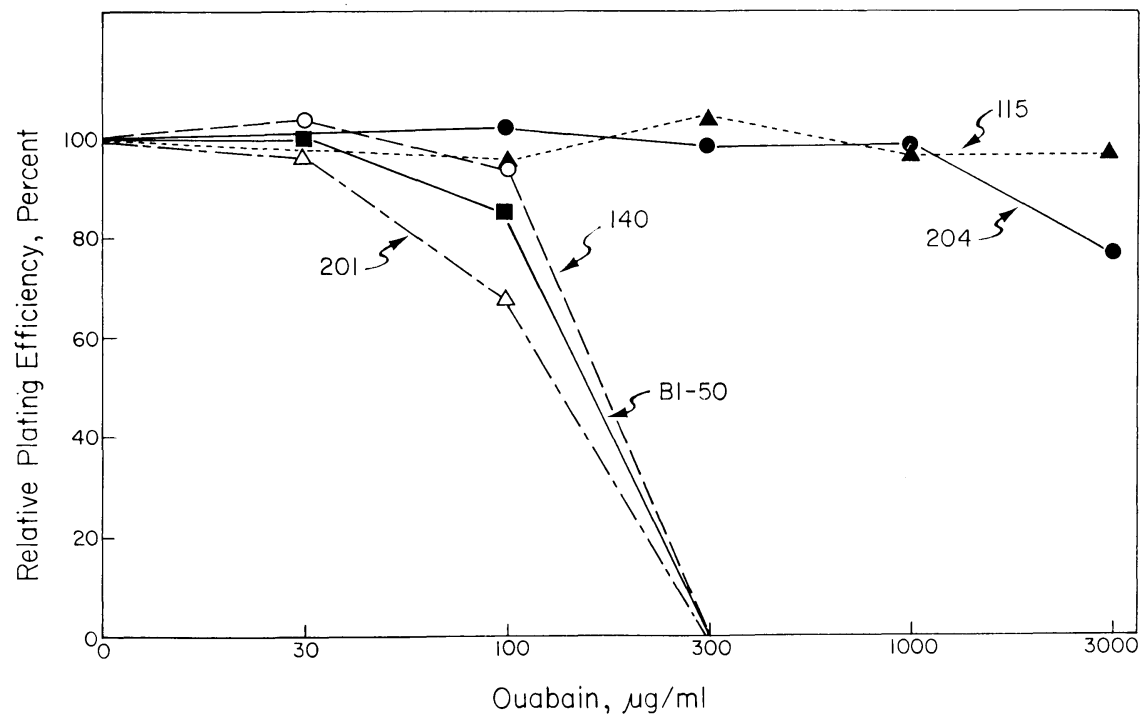

Fig. 2. Relative plating efficiency of stock cell lines in graded levels of OUA. See Fig. 1 for designation of individual lines. Each point represents an average value for counts made on three or more petri dish cultures. 


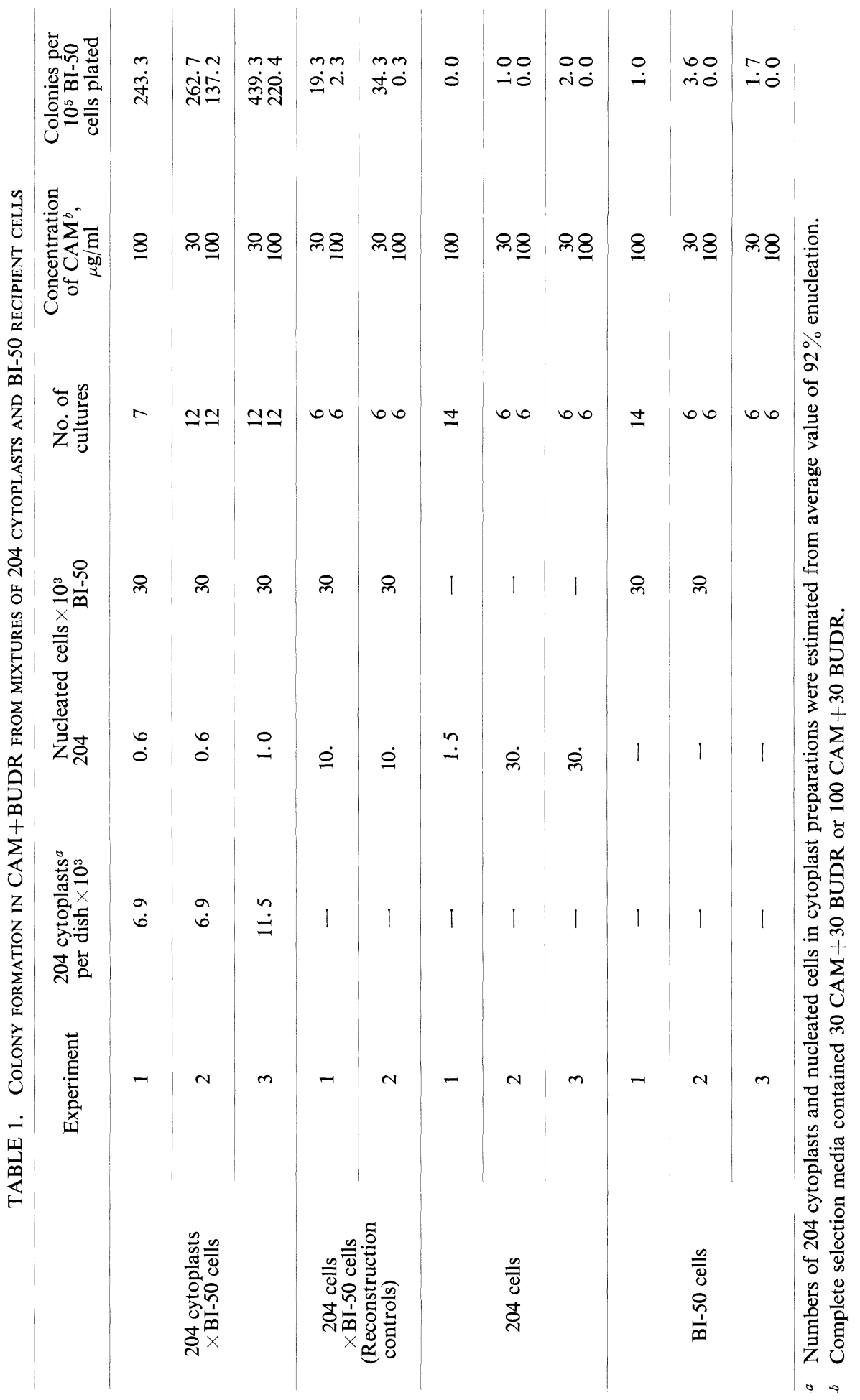


Thus, spontaneous mutation within the parental strains used could be discounted as a major factor in the production of doubly resistant cells.

Variants resistant to both CAM and BUDR did appear in significant numbers when intact parental cells were cultured together instead of separately. Dual resistance in the reconstruction controls (Table 1) exceeded background values obtained with parental cells alone, particularly if the concentration of CAM was lowered to $30 \mu \mathrm{g} / \mathrm{ml}$. In such mixtures euhybrids resistant to CAM arose by fusion between nucleated parent cells, and these gave rise by segregation to $\operatorname{BUDR}^{\mathrm{R}}$ variants $(16,18,19)$ which could proliferate in the CAM+BUDR selection medium. Similar variants could arise within mixtures of cytoplasts and recipient cells, since enucleation of donor populations by the procedure used was never quantitatively complete. After treatment with Cytochalasin B and centrifugation the cytoplast preparations always contained a small residual fraction of nucleated donor cells, and these were available to form euhybrids and segregants in the manner described. The selection of cytoplast fusion mixtures in HAT medium was designed to monitor the extent of euhybrid formation during cytohybrid assays. Table 2 shows the results obtained, along with data for mixtures of intact cells (reconstruction controls) and for parental cells alone in HAT medium. The donor component in the reconstruction series was adjusted to give a $2.5 \times$ excess of 204 cells as compared to the number estimated to be present in the cytoplast mixtures $(1.25 \times$ excess in the third control series in Table 2$)$. However, the number of colonies actually obtained from the cytoplast fusion mixtures in HAT medium was lower than would be predicted from these differentials in the number of donor cells. This disparity may reflect damage during centrifugation in the presence of Cytochalasin B, which could lower the fusion potential of some residual 204 nucleated cells that appeared to be intact morphologically. No $\mathrm{HAT}^{+}$colonies were obtained in cultures of 204 or BI-50 cells alone, even in experiments where populations up to $10^{7}$ were repeatedly plated in HAT medium (data not shown).

The incidence of BUDR ${ }^{R}$ segregants from euhybrids was not determined directly in the present experiments. However, we found the average frequency of such segregants in hybrids between $\mathrm{BUDR}^{\mathrm{R}} \times \mathrm{BUDR}^{\mathrm{S}}$ Chinese hamster cells to be $3.2 \%$ in a series of 8 lines studied earlier (16). This figure can be combined with the observed incidence of euhydrids in cytoplast fusion mixtures as shown in Table 2. A figure of $\left(3.2 \times 10^{-2}\right)\left(17.9 \times 10^{-5}\right)=5.7 \times 10^{-6}$ is thus predicted, which falls within the range of observed values for colony formation from mixtures of parent cells in $100 \mathrm{CAM}+30$ BUDR (Table 1).

Expression of $C A M^{\mathrm{R}}$ and $O U A^{\mathrm{R}}$ makers. As another baseline for evaluation, one can examine the behavior of nuclear markers in a cytoplasmic transfer system. We chose ouabain resistance for a correlated study since altered responses to the drug are assumed to originate by nuclear gene mutation (20) and there is no indication that $\mathrm{OUA}^{\mathrm{R}}$ is associated with mitochondria or other cytoplasmic organelles. In fact, recent experiments (20) show that the OUA ${ }^{R}$ marker can be transmitted to sensitive cells by the fusion of isolated metaphase chromosomes from resistant cells.

In this study we determined the incidence of resistant colonies in mixtures of 204 cytoplasts + BI-50 indicator cells, after selection in 1000 OUA + 30 BUDR, and from control cultures exposed to the same medium. The data obtained are summarized in Table 3. Colonies resistant to OUA+BUDR appeared only infrequently in these assays, and the incidence was approximately the same in cytoplast fusion mixtures and reconstruction controls (when the $2.5 \mathrm{X}$ excess of nucleated donor cells in the 


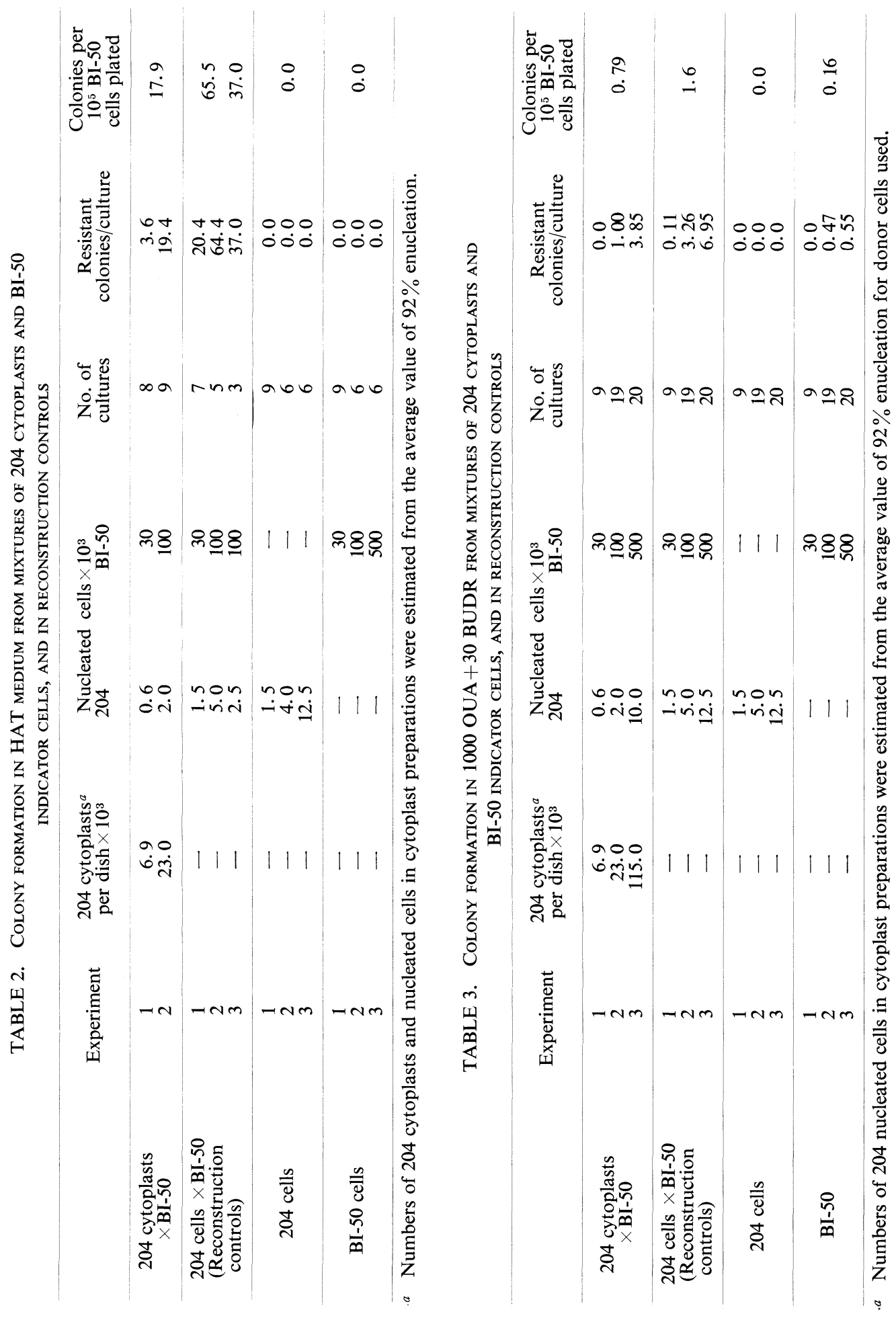


latter was taken into account). Thus, the expression of the $\mathrm{OUA}^{\mathrm{R}}$ marker in colony assays did not appear to be affected by the cytoplasmic transfer which took place from resistant to sensitive cells.

As a further check, however, the colonies that did appear in the assay cultures were isolated and characterized individually. Of these, 51 were derived from mixtures of cytoplasts + recipient cells, 13 originated from reconstruction controls, and 6 were isolated from cultures containing BI-50 cells alone. Each clone was analyzed karyotypically, and was plated out in BUDR, CAM, and OUA to determine the presence of resistance markers. On this basis, the clonal populations could be grouped together in several categories (Table 4). All the clones derived from cultures of BI-50 cells alone appeared to be spontaneous OUA $^{\mathrm{R}}$ variants; they retained sensitivity to CAM and showed the recipient cell karyotype in which small acrocentric chromosomes were missing. Similarly, clones isolated from reconstruction control cultures, with one exception, appeared to be typical euhybrids, showing large chromosome numbers, small acrocentric chromosomes from the donor source, and resistance to both CAM and OUA. Presumably the BUDR $^{\mathrm{R}}$ marker appeared in these euhybrid cells by secondary segregation.

The clones isolated from mixtures of cytoplasts and indicator cells presented a more variable picture. Of these, 14 appeared to be OUA ${ }^{\mathrm{R}}$ variants derived from unfused BI-50 cells. Another 31 clones were euhybrid in chromosome pattern, originating from the fusion of nucleated donor and recipient cells, but with secondary segregation of the BUDR ${ }^{\mathrm{R}}$ marker. Most of this series showed both $\mathrm{OUA}^{\mathrm{R}}$ and $\mathrm{CAM}^{\mathrm{R}}$ markers received from the 204 parental cells, but $3 / 31$ were sensitive to $C A M$ at $100 \mu \mathrm{g} / \mathrm{ml}$.

The last but most interesting group of clones isolated from cytoplast fusion mixtures consisted of 6 cell lines with diploid to tetraploid chromosome numbers, BI-50 karyotypes, and resistance to CAM as well as to OUA and BUDR. The presence of the $\mathrm{CAM}^{\mathrm{R}}$ marker in these cells was particularly noteworthy, since the original colonies had been isolated in OUA + BUDR alone. In principle, such variants could originate directly from BI-50 cells that had spontaneously acquired resistance to both OUA and

TABLE 4. CHARACTERISTICS OF COLONIES ISOLATED BY SELECTION WITH 1000 OUA + 30 BUDR IN DIFFERENT CULTURE SYSTEMS

\begin{tabular}{|c|c|c|c|c|}
\hline $\begin{array}{l}\text { Resistance }^{a} \\
\text { markers }\end{array}$ & Karyotype & $\begin{array}{l}204 \text { cytoplasts } \\
\times \text { BI-50 }\end{array}$ & $\begin{array}{c}204 \text { cells } \times \text { BI-50 cells } \\
\text { (Reconstruction controls) }\end{array}$ & BI-50 cells only \\
\hline \multirow{2}{*}{$\begin{array}{l}\text { BUDR }^{R} \\
\text { OUA }^{R} \\
\text { CAM }^{S}\end{array}$} & $\begin{array}{l}\text { Polyploid } \\
\text { acrocentrics } \\
\text { present }\end{array}$ & 3 & 0 & 0 \\
\hline & $\begin{array}{l}\text { Diploid, } \\
\text { acrocentrics } \\
\text { absent }\end{array}$ & 14 & 1 & 6 \\
\hline \multirow{2}{*}{$\begin{array}{l}\text { BUDR }{ }^{R} \\
\text { OUA }^{R} \\
\text { CAM }^{R}\end{array}$} & $\begin{array}{l}\text { Polyploid, } \\
\text { acrocentrics } \\
\text { present }\end{array}$ & 28 & 12 & 0 \\
\hline & $\begin{array}{l}\text { Diploid to } \\
\text { tetraploid, } \\
\text { acrocentrics } \\
\text { absent }\end{array}$ & 6 & 0 & 0 \\
\hline \multicolumn{2}{|c|}{ Total colonies } & 51 & 13 & 6 \\
\hline
\end{tabular}


CAM. However, the probability of this event was low. Using the data given in Tables 1 and 3 , the expected frequency would be $\left(1.0 \times 10^{-5}\right)\left(0.16 \times 10^{-5}\right)=0.16 \times 10^{-10}$ or less. In direct tests, no colonies were obtained from a total of $9.3 \times 10^{-7} \mathrm{BI}-50$ cells plated into medium containing $100 \mathrm{CAM}, 1000$ OUA, and 30 BUDR.

A more promising explanation is that such triply resistant cells arise by a two-step sequence in which (1) BI-50 cells mutate spontaneously to OUA ${ }^{R}$, and subsequently (2) undergo fusion with a 204 cytoplast carrying the $\mathrm{CAM}^{\mathrm{R}}$ marker. Although this interpretation seems likely, it is difficult to reconcile the observed incidence of triply resistant variants with expected frequencies for the two steps involved. For such an estimate, the frequency of $\mathrm{OUA}^{\mathrm{R}}$ mutants in $\mathrm{BI}-50$ cells may be taken as $0.16 \times 10^{-5}$ (Table 3 ) and the incidence of $\mathrm{CAM}^{\mathrm{R}}$ colonies in cytoplast fusion mixtures as approxiimately $250 \times 10^{-5}$ (Table 1$)$. Thus, the expected frequency for a 2 -step sequence would be $\left(0.16 \times 10^{-5}\right)\left(250 \times 10^{-5}\right)=4.0 \times 10^{-9}$, whereas the observed frequency (Tables 3 and 4$)$ is $6 / 51 \times\left(0.79 \times 10^{-5}\right)=0.9 \times 10^{-6}$. The basis for this discrepancy is not clear, but one possibility is that the actual frequency of cytoplast fusion in a non-selective system (e.g. OUA+BUDR) is far higher than the number of colonies which survive direct selection in CAM would suggest.

The experimental data presented thus show that background variation is an important consideration in cytoplasmic transfer studies with Chinese hamster cells. The number and kind of such variants must be known in order to evaluate transmission of cytoplasmic markers unequivocally. Secondary segregation from contaminating euhybrids in particular may contribute to colony formation in experimental assays, and would be overlooked in the absence of complete karyotypic studies. Finally, the fact that transmission of nuclear markers can be simulated by background events should serve as a warning for further studies in cytoplasmic transfer systems.

Acknowledgments. This work was supported by Grants CA 12130 and CA 05388 from the National Cancer Institute, U. S. Public Health Service. One of us (R. C. Y.) received financial aid during early phases of the work from a Babcock Fellowship, University of California, and from the Petri Foundation of New York.

\section{REFERENCES}

1. SAger, R. Cytoplasmic Genes and Organelles. Academic Press, New York, 1972.

2. Gillham, N.W. Genetic analysis of the chloroplast and mitochondrial genomes. Ann. Rev. Genetics 8, 347-392, 1974

3. BIRKY, C.W., Jr. Mitochondrial genetics in fungi and ciliates. In Genetics and Biogenesis of Mitochondria and Chloroplasts, ed. Birky, G.W., Jr., P.S. Perlman and T.J. Byers. Ohio State University Press, Columbus, pp. 182-224, 1975

4. Bunn, C.L., D.C. Wallace and J.M. Eisenstadt. Cytoplasmic inheritance of chloramphenicol resistance in mouse tissue culture cells. Proc. Natl. Acad. Sci. USA, 71, 1681-1685, 1974

6. Wallace, D.C., C.L. Bunn and J.M. Eisenstadt. Cytoplasmic transfer of chloramphenicol resistance in human tissue culture cells. J. Cell Biol. 67, 174-187, 1975

6. Bunn, C.L., D.C. Wallace and J.M. Eisenstadt. Mitotic segregation of cytoplasmic determinants for chloramphenicol resistance in mammalian cells. I: Fusions with mouse cell lines. Somatic Cell Genetics 3, 71-92, 1977

7. Wallace, D.C., C.L. Bunn and J.M. Eisenstadt. Mitotic segregation of cytoplasmic determinants for chloramphenicol resistance in mammalian cells. II: Fusions with human cell lines. Somatic Cell Genetics 3, 93-119, 1977

8. Thompson, L.H. and R.M. BAKER. Isolation of mutants from cultured mammalian cells. 
Methods in Cell Biol. 6, 209-281, 1973

9. Fulder, S.J. The measurement of spontaneous mutation in mammalian somatic cells. The Nucleus 18, 98-107, 1975

10. Humphrey, R.M. and T.C. Hsu. Further studies on biological properties of mammalian cell lines resistant to 5-bromodeoxyuridine. Texas Rpts. Biol. Med. 23 (Suppl. 1), 321, 1965

11. YU, C.K. and W.K. SinclaIR. Homogeneity and stability of chromosomes Chinese hamster cells in vitro. Canad. J. Genetics and Cytol. 6, 109-116, 1964

12. HARris, M. Effect of X-irradiation of one partner on hybrid frequency in fusions between Chinese hamster cells. J. Cell Physiol. 80, 119-128, 1972

13. Harris, M. Polyploid series of mammalian cells. Exp. Cell Res. 66, 329-336, 1971

14. LitTLEFIELD, J.W. Selection of hybrids from matings of fibroblasts in vitro and their presumed recombinants. Science 145, 709-710, 1964

15. Harris, M. Phenotypic expression of drug resistance in hybrid cells. J. Nat. Cancer Inst. 50, 423-429, 1973

16. Harris, M. Non-Mendelian segregation in hybrids between Chinese hamster cells. J. Cell. Physiol. 86, 413-430, 1975

17. Prescott, D., D. Myerson and J. Wallace. Enucleation of mammalian cells with Cytochalasin B. Exp. Cell Res. 71, 480-485, 1972

18. Marin, G. Segregation of morphological revertants in polyoma-transformed hybrid clones of hamster fibroblasts. J. Cell Sci. 9, 61-69, 1971

19. Marin, G. and P. Manduca. Synchronous replication of the parental chromosomes in a Chinese hamster-mouse somatic hybrid. Exp. Cell Res. 75, 290-292, 1972

20. Spandidos, D.A. and L. Siminovitch. Transfer of condominant markers by isolated metaphase chromosomes in Chinese hamster cells. Proc. Nat. Acad. Sci. USA 74, 3480-3484, 1977

(Received for publication, January 17, 1978) 